\title{
Relationships between Parameters of the Cardiovascular System, Salivary Lactoferrin Level and Body Temperature during a Short-Term Human Whole-Body Exposure to Cold Air
}

\author{
Liliya V. Poskotinova, $\mathrm{PhD}$, ScD*; Elena V. Krivonogova, PhD; Olga V. Krivonogova; \\ Denis B. Demin, PhD, ScD; Irina N. Gorenko; Elena V. Tipisova, $\mathrm{PhD}, \mathrm{ScD}$; \\ Victoria A. Popkova, PhD; Alexandra E. Elfimova, PhD \\ N. Laverov Federal Center for Integrated Arctic Research FCIARctic of the RAS \\ Arkhangelsk, Russia
}

\begin{abstract}
Background: The problem of maintaining body temperature in people working outdoors in the cold air of the Arctic remains relevant. The purpose of this study was to determine the autonomic nervous mechanisms of regulation of heart rate (HR), blood pressure (BP) and local immunity on the example of the dynamics of salivary lactoferrin during a decrease in body temperature in humans (the core and the skin of hands) during and after a short-term, whole-body exposure to cold air.

Materials and Methods: A total of 15 healthy Russian male volunteers aged between 18 and 20 years, born and living in Arkhangelsk, were examined in the winter. Research stages: the registration of indicators before exposure to the cold air (Stage 1), during the 10-minute exposure to the cold air at $-20^{\circ} \mathrm{C}$ (Stage 2) and after the 10-minute exposure to the cold air (Stage 3). The registration of indicators in Stages 1 and 3 was carried out indoors at an air temperature of $+20^{\circ} \mathrm{C}$. HR (bpm), the heart rate variability (HRV) parameters, systolic and diastolic blood pressure (BPsyst, BPdiast, $\mathrm{mm} \mathrm{Hg}$ ), salivary lactoferrin level (ng/ml) by ELISA and the body temperature in the ear canal (Tear, ${ }^{\circ} \mathrm{C}$ ) and on the skin of the dorsum of the right hand (Tskin, ${ }^{\circ} \mathrm{C}$ ) were determined at each stage of the study.

Results: In Stage 2 with significantly decreased Tear and Tskin, compared to the initial indicators in Stage 1, there was a significant increase in HRV indices reflecting the overall HRV and vagal effects on the heart rhythm. At the same time, HR was significantly decreased, as well as stress index. An increase in the total power (TP) of the HRV spectrum was revealed due to a predominant increase in HF and VLF, and to a lesser degree in LF. Both BPsyst and BPdiast significantly increased. After cooling in Stage 3, HR increased, but remained significantly lower than the initial values. The overall HRV according to SDNN and TP decreased, reaching baseline values. Concentrations of salivary lactoferrin during cooling in Stage 2 tended to increase, which was also maintained in Step 3 after cooling. Correlation analysis in the entire sample $(\mathrm{n}=15)$ revealed a positive correlation between SDNN and Tear in Stage $2\left(\mathrm{r}_{\mathrm{s}}=0.56, P=0.035\right)$. In Stage 2, the change in Tskin was significantly correlated with the salivary lactoferrin level $\left(\mathrm{r}_{\mathrm{s}}=-0.73, P=0.003\right)$; this relationship was also found in Stage $3\left(\mathrm{r}_{\mathrm{s}}=-0.65, P=0.015\right)$.

Conclusion: The successful return of body temperature after general cooling occurs under the condition of increasing the overall HRV, enhancing vagal influences on the heart rhythm, HF and VLF components of HRV during cooling. An increase in the level of salivary lactoferrin, while maintaining vagal reserves of the vegetative regulation of heart rhythm against a decrease in skin temperature during general cooling, as well as a decrease in the level of lactoferrin against the background of recovery of body temperature after cooling, at least 10 minutes, can be regarded as an adaptive response of the body to exposure to cold temperature with minimal risk of cold inflammation. (International Journal of Biomedicine. 2019;9(2):111-116.)
\end{abstract}

Key Words: heart rate variability $\bullet$ heart rate $\bullet$ blood pressure $\bullet$ salivary lactoferrin $\bullet$ exposure to cold air

\section{Abbreviations}

BP, blood pressure; CIG, cardiointervalogram; HR, heart rate; HRV, heart rate variability; SI, stress index; TP, total power 


\section{Introduction}

General cooling of the human body can cause different ratios between the activity of the neurophysiological mechanisms, sympathetic and parasympathetic regulation of heart rhythm and vascular tone, ${ }^{(1-4)}$ and mobilization of the immune system in the form of enhanced pro- and anti-inflammatory reactions. ${ }^{(5)}$ Against the background of general cooling, the core body temperature is maintained through increased vasoconstriction in peripheral tissues (skin, subcutaneous fat) and an increase in BP. It is believed that stable, increased BP in Arctic residents subjected to moderate exposure to cold $\left(-10^{\circ} \mathrm{C}\right)$ may not lead to aggravation of symptoms of arterial hypertension, as this action reduces the body's sympathetic response to exposure to cold ${ }^{(6)}$ However, an excessive redistribution of blood supply, to the detriment of blood supply to peripheral tissues, can lead to impaired microcirculation, pronounced activation of inflammatory reactions up to necrosis of supercooled parts of the body. Thus, there is the problem of determining the physiological criteria for the balance of autonomic-immune relationships that maintain body temperature and the immune response under conditions of general cooling.

Lactoferrin in the biosubstrates of a living organism reflects the process of the acute phase of inflammation and activation of local nonspecific immunity - in particular, the activity of phagocytosis in response to the stress factorand also regulates the effect of redistribution of immune competent cells during cooling. ${ }^{(7,8)}$ The level of lactoferrin in biosubstrates is a marker of stress-induced modulation of congenital secretory immune response, the dynamics of which determines a person's susceptibility to infectious diseases under stress. ${ }^{(9)}$ The consumption of food enriched with lactoferrin contributes to the preservation of the daily rhythm of the bioelectric structures of the brain under stress, ${ }^{(10)}$ and its prior introduction into the tissues of the body reduces the stress-induced effects of cortisol. ${ }^{(8)}$ When exercising on the background of high levels of cortisol, the level of lactoferrin may increase, ${ }^{(11)}$ decrease ${ }^{(12)}$ or remain stable ${ }^{(13)}$ — which level occurs is associated with different stress-reactivity of the immune and autonomous nervous systems of the human body. Currently, the conditions of the optimal ratio of the parameters of the cardiovascular system and immune factors to maintain temperature of the corpus and peripheral tissues of the human body during experimental exposure to cold air have not been determined.

The purpose of this study was to determine the autonomic nervous mechanisms of regulation of HR, BP and local immunity on the example of the dynamics of salivary lactoferrin during a decrease in body temperature in humans (the core and the skin of hands) during and after a short-term, whole-body exposure to cold air.

\section{Materials and Methods}

A total of 15 healthy Russian male volunteers aged between 18 and 20 years, born and living in Arkhangelsk, were examined in the winter. Volunteers had no signs of deficiency or excessive body weight (BMI of $18.5-25 \mathrm{~kg} / \mathrm{m}^{2}$ ), or fever (axillary temperature $\leq 37^{\circ} \mathrm{C}$ ) and inflammatory processes of the oral cavity.

The study was conducted in accordance with ethical principles of the WMA Declaration of Helsinki (1964, ed. 2013) and approved by the FCIARctic Ethics Committee. Written informed consent was obtained from all participants.

The study stages were conducted in the morning between 9.30AM and 12.00AM and included the registration of indicators before (1), during (2) and after the 10-minute exposure to the cold air (3). Volunteers dressed in underwear, cotton trousers, winter boots and a cotton robe were examined in a sitting position at resting-state. The registration of indicators in Stages 1 and 3 was carried out indoors at an air temperature of $+20^{\circ} \mathrm{C}$. The registration of indicators in Stage 2 was carried out in a cold chamber at $-20^{\circ} \mathrm{C}$. Determining the body temperature in the ear canal $\left(\mathrm{Tear},{ }^{\circ} \mathrm{C}\right)$ and on the skin of the dorsum of the right hand (Tskin, ${ }^{\circ} \mathrm{C}$ ) was performed using a B.Well WF-1000 medical electronic infrared thermometer (Switzerland) before entering the chamber (Stage 1), on the 10th minute of being in the chamber (Stage 2) and the 10th minute after leaving the chamber (Stage 3). The thermometer was installed in the ear canal and on the skin of the hand perpendicular to the surface of the body.

We calculated additional indicators that demonstrate the degree of preservation of body temperature during cooling in Stage 2 - Tear $\%$ and Tskin $\%$.

Tear $\%=\operatorname{Tear}(2) / \operatorname{Tear}(1) \times 100 \%$, where Tear $(2)$ is the temperature value in the ear canal in Stage 2, Tear (1) is the temperature value in the right ear canal in Stage 1.

Tskin $\%=$ Tskin $(2) /$ Tskin $(1) \times 100 \%$, where Tskin (2) is the temperature value on the skin of the dorsum of the right hand in Stage 2, Tskin (1) is the temperature value on the skin of the dorsum of the right hand in Stage 1.The high rates of Tear $\%$ and Tskin $\%$ indicated good preservation of body temperature when exposed to cold.

The registration of the cardiointervalograms (CIG) was performed during 5 minutes before entering the chamber (Stage 1), 10 minutes in the chamber (Stage 2 ) and 6-10 minutes (during 5 minutes) after leaving the chamber (Stage 3). For the possibility of CIG recording under cold room conditions, a one-lead electrocardiogram channel of the Neuron-SpectrumSM device (Neurosoft, Russia), placed in a tank with thermal insulation, was used. Subsequently, CIGs of the last 5 minutes in the cold chamber and Stages 1 and 3 were processed using the Varicard instrument software (Ramena, Russia), and the HRV parameters were calculated. ${ }^{(14)}$

The following HRV parameters were evaluated: $\mathrm{HR}$ - heart rate, bpm; RMSSD (ms) - the root mean square differences of successive R-R intervals; SDNN (msec) - the standard deviation of the normal-to-normal RR intervals; SI (unit) - Stress Index, calculated by the formula $[\mathrm{SI}=\mathrm{Amo} 50 / 2 \times \mathrm{VAR} \times \mathrm{Mo}$, where Mo (MS) is the cardiointerval value dividing the CIG series in half, VAR - variation range between the minimum and maximum values in the CIG series, and Amo50,\% -amplitude of mode number of R-R intervals]; TP $\left(\mathrm{ms}^{2}\right)$ - Total Power, HF $\left(\mathrm{ms}^{2}\right)$ - high frequency power of HRV $(0.15$ to $0.40 \mathrm{~Hz})$; LF $\left(\mathrm{ms}^{2}\right)$ - low-frequency power of HRV $(0.04-0.155 \mathrm{~Hz})$; VLF $\left(\mathrm{ms}^{2}\right)-$ 
very low frequency power of HRV $(0.0033-0.04 \mathrm{~Hz})$.

With short CIG recordings (up to $5 \mathrm{~min}$ ), the SDNN, RMSSD, TP indices reflect both the general reactivity of the vegetative regulation of the heart rhythm and the parasympathetic activity. The HF HRV power spectrum or respiratory band coincides with respiration as the parasympathetic nervous system operates using signaling mechanisms that can change HR in phase with respiration. The LF index shows baroreflex activity with the predominant participation of the sympathetic centers of vegetative regulation. Stress Index is associated with increased sympathetic activity. VLF index indicates the activity of humoral regulation of heart rhythm, the activity of thermogenesis, endothelial function and renin-angiotensin mechanism. ${ }^{(15,16)}$

BP (systolic - BPsyst and diastolic - BPdiast) was determined using an A\&D medical device (Japan) before entering the chamber, immediately after leaving the chamber and in the 10th minute after leaving the chamber.

The saliva was collected on an empty stomach before entering the cold chamber, immediately after leaving the chamber and in the 10th minute after leaving the chamber. The collected samples of saliva were stored in eppendorfs at $-20{ }^{\circ} \mathrm{C}$, then immediately before analysis were thawed and centrifuged at 3,000 rpm for 15 minutes. Biological material was taken from the middle of the eppendorf for further analysis, without touching the walls and sediment at the bottom of the tube. The level of lactoferrin in saliva $(\mathrm{ng} / \mathrm{ml})$ was determined by ELISA using One-plate Fully Automated ELISA Analyzer (Elisys Uno; Human, Germany) and a commercial test kit (Hycult biotechnology b.v.; Netherlands) with a 20-fold dilution of samples using solution for dilution (Sample Dilution buffer), which is part of the test kit.

Statistical analysis was performed using the statistical software «STATISTICA 10». The normality of distribution of continuous variables was tested by Shapiro-Wilk's W test. Median (Me), interquartile range (IQR; 25th to 75th percentiles), and the $95 \%$ confidence interval $(95 \% \mathrm{CI})$ were calculated. Spearman's rank correlation coefficient $\left(\mathrm{r}_{\mathrm{s}}\right)$ was calculated to measure the strength and direction of the relationship between two variables. The Friedman Test was used to test for differences between 3 dependent samples. A probability value of $P<0.017$ was considered statistically significant.

\section{Results}

Table 1 presents the parameters of HRV, blood pressure, body temperature and salivary lactoferrin levels on the study stages. When exposed to cold in Stage 2, compared to the initial indicators in Stage 1, there was a significant increase in HRV indices reflecting the overall HRV and vagal effects on the heart rhythm: SDNN $\left(P_{1-2}<0.001\right)$, RMSSD $\left(P_{1-2}<0.001\right)$, and TP $\left(P_{1-2}=0.004\right)$. At the same time, HR was significantly decreased $\left(P_{1-2}<0.001\right)$, as well as SI $\left(P_{1-2}=0.004\right)$. An increase in the TP of the HRV spectrum was revealed due to a predominant increase in $\operatorname{HF}\left(P_{1-2}<0.001\right)$ and $\operatorname{VLF}\left(P_{1-2}=0.012\right)$, and to a lesser degree in $\operatorname{LF}\left(P_{1-2}=0.017\right)$. Both BPsyst and BPdiast significantly increased $\left(P_{1-2}=0.005\right)$. The temperature of Tear and Tskin decreased significantly with total cooling $\left(P_{1-2}<0.001\right)$.

After cooling in Stage 3, HR increased $\left(P_{2-3}=0.001\right)$, but remained significantly lower than the initial values $\left(P_{1}\right.$. $\left.{ }_{3}<0.001\right)$. The overall HRV according to SDNN and TP decreased, reaching baseline values $\left(P_{2-3}<0.001\right.$ and $P_{2-3}=0.003$, respectively). Indicators of RMSSD and HF, which characterize vagal activity, despite a significant decrease, remained elevated relative to baseline values $\left(P_{1-3}=0.010\right.$ and $P_{1-3}=0.008$, respectively). Indicators of SI and LF, reflecting sympathetic activity, increased $\left(P_{2-3}=0.002\right.$ and $P_{2-3}=0.009$, respectively) to the level of baseline values. VLF and BPsyst, despite the downward trend, had large intragroup differences; therefore, in general, they did not achieve a significant decrease by the 10th minute after exposure to cold $\left(P_{2-3}=0.069\right.$ and $P_{2-3}=0.033$, respectively). BPdiast after exposure to cold significantly decreased to baseline values $\left(P_{2-3}<0.001\right)$. The temperatures Tear and Tskin increased significantly after cooling; however, these values remained lower compared to background values $\left(P_{1-3}<0.001\right)$.

Concentrations of salivary lactoferrin during cooling in Stage 2 tended to increase $(P>0.05)$, which was also maintained in Step 3 after cooling. An individual analysis of baseline levels of lactoferrin revealed that 3 people had a significant excess of the value of 75th percentile $(1203.6 \mathrm{ng} / \mathrm{ml}, 1482.6 \mathrm{ng} / \mathrm{ml}$ and $1805.6 \mathrm{ng} / \mathrm{ml}$ ). In these 3 people during cooling, the dynamics of lactoferrin was found to be opposite to that of the whole group: a decrease in concentration instead of increasing. With the exclusion of these individuals from the sample $(n=12)$, the increase in the level of lactoferrin was more pronounced - from $202.2(41.8 ; 693.4) \mathrm{ng} / \mathrm{ml}$ to $1038.0(257.6 ; 1934.0) \mathrm{ng} / \mathrm{ml}$, $P=0.026$. In Stage 3, the lactoferrin level was almost unchanged - $1066.0(91.2 ; 1787.2) \mathrm{ng} / \mathrm{ml}$.

Correlation analysis in the entire sample $(\mathrm{n}=15)$ revealed a positive correlation between SDNN and Tear in Stage 2 $\left(\mathrm{r}_{\mathrm{s}}=0.56, P=0.035\right)$. RMSSD and SDNN in Stage 2 correlated with Tear in Stage $3\left(\mathrm{r}_{\mathrm{s}}=0.57, P=0.035 ; \mathrm{r}_{\mathrm{s}}=0.61, P=0.020\right.$, respectively). The HF, VLF and SI indicators in Stage 2 were also in correlation with Tear in Stage 3: $\mathrm{r}_{\mathrm{s}}=0.64(P=0.014)$, $\mathrm{r}_{\mathrm{s}}=0.62(P=0.019)$, and $\left.\mathrm{r}_{\mathrm{s}}=-0,60(P=0.023)\right)$, respectively.

Significant correlations of HRV indices and Tskin during cooling and after it were not revealed. However, Tskin dynamics was associated with changes in the level of salivary lactoferrin. In Stage 2, the change in Tskin was significantly correlated with the salivary lactoferrin level $\left(\mathrm{r}_{\mathrm{s}}=-0.73\right.$, $P=0.003)$; this relationship was also found in Stage $3\left(\mathrm{r}_{\mathrm{s}}=-\right.$ $0.65, P=0.015)$. An inverse correlation was found between Tskin $\%$ and the salivary lactoferrin level in Stage $3\left(\mathrm{r}_{\mathrm{s}}=-0.72\right.$, $P=0.008$ ).

The relationship between salivary lactoferrin levels and cardiovascular parameters during cooling was multidirectional. Exclusion from the group of 3 people with baseline high levels of lactoferrin (more than 75th percentile) allowed us to obtain significant correlations between these indicators in a sample of 12 people.

Thus, an increase in BPdiast was associated with an increase in lactoferrin level in Stage $2\left(\mathrm{r}_{\mathrm{s}}=0.61, P=0.047\right)$. The remaining correlations reflected the relationship between 
the lactoferrin dynamics upon cooling with baseline levels of HRV parameters. Thus, the level of lactoferrin in Stage 2 negatively correlated with the indicators of RMSSD, SDNN, and HF in Stage 1: $\mathrm{r}_{\mathrm{s}}=-0.75(P=0.007), \mathrm{r}_{\mathrm{s}}=-0.65(P=0.031)$, $\mathrm{r}_{\mathrm{s}}=-0,64(P=0.028)$, respectively.

\section{Table 1.}

Parameters of HRV, blood pressure, body temperature and salivary lactoferrin levels on the study stages (Me, IQR $\left[P_{25} ; P_{75}\right]$ )

\begin{tabular}{|c|c|c|c|c|}
\hline Variable & Stage 1 & Stage 2 & Stage 3 & $P$-value \\
\hline $\begin{array}{l}\text { HR, } \\
\text { bpm }\end{array}$ & $\begin{array}{c}74.5 \\
(69.1 ; 79.0)\end{array}$ & $\begin{array}{c}59.0 \\
(57.0 ; 62.0)\end{array}$ & $\begin{array}{c}65.4 \\
(62.4 ; 70.2)\end{array}$ & $\begin{array}{l}\mathrm{P}_{1-2}<0.001 \\
\mathrm{P}_{2-3}=0.001 \\
\mathrm{P}_{1-3}<0.001\end{array}$ \\
\hline $\begin{array}{l}\text { SDNN, } \\
\mathrm{ms}\end{array}$ & $\begin{array}{c}53.8 \\
(40.9 ; 68.1)\end{array}$ & $\begin{array}{c}82.8 \\
(71.8 ; 131.4)\end{array}$ & $\begin{array}{c}51.78 \\
(36.5 ; 76.1)\end{array}$ & $\begin{array}{l}\mathrm{P}_{1-2}<0.001 \\
\mathrm{P}_{2-2}<0.001 \\
\mathrm{P}_{1-3}=0.070\end{array}$ \\
\hline $\begin{array}{l}\text { RMSSD, } \\
\text { ms }\end{array}$ & $\begin{array}{c}34.39 \\
(22.79 ; 48.48)\end{array}$ & $\begin{array}{c}57.95 \\
(47.99 ; 82.01)\end{array}$ & $\begin{array}{c}47.23 \\
(28.24 ; 56.43)\end{array}$ & $\begin{array}{l}\mathrm{P}_{1-2}<0.001 \\
\mathrm{P}_{2-2}=0.009 \\
\mathrm{P}_{1-3}=0.010\end{array}$ \\
\hline $\begin{array}{l}\text { Stress Index, } \\
\text { unit }\end{array}$ & $\begin{array}{c}84.2 \\
(54.0 ; 177.9)\end{array}$ & $\begin{array}{c}39.2 \\
(17.6 ; 56.2)\end{array}$ & $\begin{array}{c}76.33 \\
(41.76 ; 142.77)\end{array}$ & $\begin{array}{l}\mathrm{P}_{1-2}=0.002 \\
\mathrm{P}^{2-3}=0.002 \\
\mathrm{P}_{1-3}=0.191\end{array}$ \\
\hline $\begin{array}{l}\text { TP, } \\
\times 1000, \mathrm{~ms}^{2}\end{array}$ & $\begin{array}{c}2.75 \\
(1.46 ; 3.85)\end{array}$ & $\begin{array}{c}4.88 \\
(2.97 ; 13.9)\end{array}$ & $\begin{array}{c}2.85 \\
(1.80 ; 4.61)\end{array}$ & $\begin{array}{l}\mathrm{P}_{1-2}=0.004 \\
\mathrm{P}^{2-3}=0.003 \\
\mathrm{P}_{1-3}=0.232\end{array}$ \\
\hline $\begin{array}{l}\mathrm{HF}, \times 1000, \\
\mathrm{~ms}^{2}\end{array}$ & $\begin{array}{c}0.42 \\
(0.22 ; 0.84)\end{array}$ & $\begin{array}{c}1.49 \\
(0.85 ; 2.02)\end{array}$ & $\begin{array}{c}0.76 \\
(0.38 ; 1.23)\end{array}$ & $\begin{array}{l}\mathrm{P}_{1-2}<0.001 \\
\mathrm{P}_{2-2}=0.001 \\
\mathrm{P}_{1-3}=0.008\end{array}$ \\
\hline $\begin{array}{l}\mathrm{LF}, \\
\times 1000, \mathrm{~ms}^{2}\end{array}$ & $\begin{array}{c}1.11 \\
(0.66 ; 1.79)\end{array}$ & $\begin{array}{c}1.52 \\
(0.84 ; 4.89)\end{array}$ & $\begin{array}{c}1.17 \\
(0.67 ; 1.62)\end{array}$ & $\begin{array}{l}\mathrm{P}_{1-2}=0.017 \\
\mathrm{P}_{2-3}=0.009 \\
\mathrm{P}_{1-3}=0.776\end{array}$ \\
\hline $\begin{array}{l}\text { VLF, } \\
\times 1000, \mathrm{~ms}^{2}\end{array}$ & $\begin{array}{c}0.39 \\
(0.26 ; 0.85)\end{array}$ & $\begin{array}{c}0.71 \\
(0.43 ; 2.77)\end{array}$ & $\begin{array}{c}0.64 \\
(0.35 ; 0.80)\end{array}$ & $\begin{array}{l}\mathrm{P}_{1-2}=0.012 \\
\mathrm{P}_{2-3}=0.069 \\
\mathrm{P}_{1-3}=0.256\end{array}$ \\
\hline $\begin{array}{l}\text { BPsyst, } \\
\mathrm{mm} \mathrm{Hg}\end{array}$ & $\begin{array}{c}122.0 \\
(117.0 ; 130.0)\end{array}$ & $\begin{array}{c}132.0 \\
(123.0 ; 138.0)\end{array}$ & $\begin{array}{c}125.0 \\
(120 ; 130)\end{array}$ & $\begin{array}{l}\mathrm{P}_{1-2}=0.005 \\
\mathrm{P}_{2-2}=0.033 \\
\mathrm{P}_{1-3}=0.781\end{array}$ \\
\hline $\begin{array}{l}\text { BPdiast, } \\
\mathrm{mm} \mathrm{Hg}\end{array}$ & $\begin{array}{c}83.0 \\
(81.0 ; 86.0)\end{array}$ & $\begin{array}{c}92.0 \\
(85.0 ; 102.0)\end{array}$ & $\begin{array}{c}89.0 \\
(78.0 ; 90)\end{array}$ & $\begin{array}{l}\mathrm{P}_{1-2}=0.005 \\
\mathrm{P}_{2-3}<0.001 \\
\mathrm{P}_{1-3}=0.285\end{array}$ \\
\hline Tear, ${ }^{\circ} \mathrm{C}$ & $\begin{array}{c}36.3 \\
(36.1 ; 36.4)\end{array}$ & $\begin{array}{c}34.7 \\
(33.8 ; 35.4)\end{array}$ & $\begin{array}{c}35.6 \\
(35.5 ; 36.1)\end{array}$ & $\begin{array}{l}\mathrm{P}_{1-2}<0.001 \\
\mathrm{P}_{2-2}=0.001 \\
\mathrm{P}_{1-3}<0.001\end{array}$ \\
\hline Tskin, ${ }^{\circ} \mathrm{C}$ & $\begin{array}{c}33.0 \\
(27.0 ; 35.7)\end{array}$ & $\begin{array}{c}19.1 \\
(17.0 ; 20.8)\end{array}$ & $\begin{array}{c}23.9 \\
(22.8 ; 26.7)\end{array}$ & $\begin{array}{l}\mathrm{P}_{1-2}<0.001 \\
\mathrm{P}_{2-3}<0.001 \\
\mathrm{P}_{1-3}<0.001\end{array}$ \\
\hline $\begin{array}{l}\text { Lactoferrin, } \\
\mathrm{ng} / \mathrm{ml}\end{array}$ & $\begin{array}{c}496.0 \\
(90.0 ; 917.4)\end{array}$ & $\begin{array}{c}910.7 \\
(257.6 ; 1867.8)\end{array}$ & $\begin{array}{c}1081.3 \\
(148.0 ; 1765.2)\end{array}$ & $\begin{array}{l}\mathrm{P}_{1-2}=0.157 \\
\mathrm{P}^{2-2}=0.753 \\
\mathrm{P}_{1-3}=0.116\end{array}$ \\
\hline
\end{tabular}

\section{Discussion}

Increased blood pressure, especially BPdiast, is a natural reaction of the body in response to vasoconstriction in peripheral tissues, wherein the processes of thermogenesis, the renin-angiotensin mechanism, and endothelial function are activated. This was reflected in our study in an increase in the VLF component of HRV. ${ }^{(15,16)}$ The enhancement of the HRV VLF component during cooling reflected the adaptive response of the body, confirmed by the correlation analysis: the higher VLF was during cooling, the stronger trend towards the original body temperature values was found 10 minutes after leaving the cold chamber. In response to an increase in blood pressure, the arterial baroreflex was activated, which led to a decrease in HR. An increase in the LF component of HRV has traditionally been associated with the activation of the baroreflex ${ }^{(6,15)}$ but in our study there was no significant correlation between this part of HRV and body temperature indices either during cooling or after it. At the same time, an increase in HF components of HRV during cooling is associated with an increase in body temperature at the warming stage after exposure to cold. This may indicate that the frequency range of the arterial baroreflex is consistent with the HF component of HRV $(0.15-0.40 \mathrm{~Hz})$ during cold exposure, which reflects the activation of respiration during hypoxia. ${ }^{(17)}$ The results obtained for changes in the cardiovascular system with general air cooling are in tune with the results of studying a different type of cold exposure in the form of an isolated face cooling, when BP rises and HR decreases. ${ }^{(1)}$ However, Hodjes et al., with a general human cooling at a temperature of $0^{\circ} \mathrm{C}$ for 30 minutes, found an increase in the LF and HF components, as well as RMSSD against the background of an increased HR. ${ }^{(18)}$ These results show clearly that neurovegetative changes in humans depend on the level of temperature and the duration of cold temperature exposure. The vegetative manifestations we observed during general cooling differed from changes in HRV during local cooling of the head when an increase in sympathetic activity was observed against the background of a decrease in total HRV ${ }^{(19)}$ We observed no increase in vagal activity in 3 people with a high baseline level of lactoferrin (more than 75th percentile), in which SI was either elevated or did not significantly change against the background of stable values during the whole observation. A decrease in the sympathetic pressor response and an activation of the parasympathetic response to the cold is regarded as an adaptive response to cold in both the Aborigines and the newcomers of the Arctic. ${ }^{(1)}$ Thus, the successful return of body temperature after general cooling occurs under the condition of increasing the overall HRV, enhancing vagal influences on the heart rhythm, HF and VLF components of HRV during cooling.

A moderate increase in the level of lactoferrin as a marker of the secretory response in stress-induced activation of local immunity is recognized as logical. Thus, Bosch et al. ${ }^{(9)}$ revealed an increase in the lactoferrin secretion against the background of increased vagal activity, according to HRV during stress with low emotionality and against the background of increased sympathetic activity during stress with high emotionality among volunteers. However, with a pronounced sympathoadrenal stress reaction, the level of lactoferrin may decrease. ${ }^{(13)}$ In our study, the presence of a significant correlation between skin temperature and lactoferrin level reflects the importance of transferrin system activation with 
a moderate baseline as a response to the pro-inflammatory effect of cold hypoxia of peripheral tissues. The correlation of lactoferrin and BPdiast suggests that the greater BPdiast due to cold vasoconstriction, the more pronounced the oxidative processes due to cold hypoxia in the tissues. Moreover, if the skin temperature fell lower and BPdiast increased, the increase in salivary lactoferrin was more pronounced, which reflected the intensity of oxidative processes in the tissues, not only during cooling, but also in the 10th minute of warming. Data of correlation analysis showed that pronounced vagal activity in humans before exposure to cold contributes to repression of the level of growth of lactoferrin, reflecting the activity of local immune responses during exposure to cold. Stress-protective effects of lactoferrin administration before stress are known, in particular, the severity of inflammation decreases with subsequent exposure to stress. ${ }^{(20)}$ However, the presence of marginal high basic values of salivary lactoferrin may reflect a pronounced activity of oxidative processes during the development of inflammation in the tissues, which does not allow an adequate vascular and immune response to develop with subsequent exposure to cold and to ensure the preservation of body temperature. Therefore, the focus of vegetative and immune reactions in individuals with a high baseline lactoferrin level (more than 75th percentile)in terms of adaptation and/or maladaptation at low temperatures needs further special study.

Thus, the maintenance of body temperature during short-term $(10 \mathrm{~min})$ general air cooling at $-20{ }^{\circ} \mathrm{C}$ is ensured by the activation of vagal influences in combination with the enhancement of suprasegmental regulatory influences on the heart rhythm. An increase in the level of salivary lactoferrin, while maintaining vagal reserves of the vegetative regulation of heart rhythm against a decrease in skin temperature during general cooling, as well as a decrease in the level of lactoferrin against the background of recovery of body temperature after cooling, at least 10 minutes, can be regarded as an adaptive response of the body to exposure to cold temperature with minimal risk of cold inflammation. The data obtained reflect the need to use health-saving technologies to enhance vagal influences on the heart rhythm to restrain the pressor response of the sympathetic nervous system, maintain body temperature in cold conditions and minimize the cold-dependent inflammatory reactions in peripheral tissues.

\section{Competing Interests} interests.

The authors declare that they have no competing

\section{Sources of Funding}

The reported study was funded by the FCIARctic according to the research project No 115050610141 .

\section{Acknowledgments}

We would like to thank M.A. Ovsyankina, L.K. Dobrodeeva, and A.V. Samodova for their assistance in this study.

\section{References}

1. Le Blanc J, Dulac S, Cote J, Girard B. Autonomic nervous system and adaptation to cold in man. J ApplPhysiol. 1975;39(2):181-6. doi:10.1152/jappl.1975.39.2.181.

2. Demin DB, Poskotinova LV, Krivonogova EV. [Variants of neurophysiological reactions during short-term experimental hypothermia in humans]. J Biomedical Radioelectronics. 2018;12:48-50. doi: 10.18127/j15604136-201812-06. [Article in Russian].

3. Mäkinen TM, Mäntysaari M, Pääkkönen T, Jokelainen J, Palinkas LA, Hassi J, Leppäluoto J, Tahvanainen K, Rintamäki $\mathrm{H}$. Autonomic nervous function during whole-body cold exposure before and after cold acclimation. Aviat Space Environ Med. 2008;79(9):875-82.

4. Peng RC, Yan WR, Zhou XL, Zhang NL, Lin WH, Zhang YT. Time-frequency analysis of heart rate variability during the cold pressor test using a time-varying autoregressive model. Physiol Meas. 2015 Mar;36(3):441-52. doi: 10.1088/09673334/36/3/441.

5. Patrakeeva VP, Basova EE. Effects of Low Temperatures on the Formation of Adaptive Reactions: A Review. International Journal of Biomedicine. 2018;8(2):95-101. doi: 10.21103/Article8(2)_RA1.

6. Hintsala HE, Kiviniemi AM, Tulppo MP, Helakari H, Rintamämaki H, Mäntysaari M, et al. Hypertension Does Not Alter the Increase in Cardiac Baroreflex Sensitivity Caused by Moderate Cold Exposure. Front Physiol. 2016;7:204. doi: 10.3389/fphys.2016.00204.

7. Kuznetsov IA, Potiyevskaya VI, Kachanov IV, Kuraleva OO. [Laktoferrin's role in biological circles of the person. Modern problems of sciences and education]. 2017:3 [Electronic source] http://www.science-education.ru/ru/ article/view?id=26522. [Article in Russian].

8. Aleshina GM, Yankelevich IA, Zhakharova ET, Kokryakov VN. [Stress-protective effect of human lactoferrin]. Ross Fiziol Zh Im I M Sechenova. 2016;102(7):846-51. [Article in Russian].

9. Bosch JA, de Geus EJ, Veerman EC, Hoogstratan J, Nieuw Amerongen AV. Innate secretory immunity in response to laboratory stressors that evoke distinct patterns of cardiac autonomic activity. Psychosom Med. 2003;65(2):245-58.

10. Thompson RS, Roller R, Mika A, Greenwood BN, Knight $\mathrm{R}$, Chichlowski M, et al. Dietary Prebiotics and Bioactive Milk Fractions Improve NREM Sleep, Enhance REM Sleep Rebound and Attenuate the Stress-Induced Decrease in Diurnal Temperature and Gut Microbial Alpha Diversity. Front Behav Neurosci. 2017;10:240. doi: 10.3389/fnbeh.2016.00240.

11. Li CY, Hsu GS, Suzuki K, Ko MH, Fang SH. Salivary Immuno Factors, Cortisol and Testosterone Responses in Athletes of a Competitive 5,000 m Race. Chin J Physiol. 2015; 58(4):263-9. doi: 10.4077/CJP.2015.BAE367.

12. He CS, Tsai ML, Ko MH, Chang CK, Fang SH. Relationships among salivary immunoglobulin A, lactoferrin and cortisol in basketball players during a basketball season. Eur J Appl Physiol. 2010;110(5):989-95. doi: 10.1007/s00421010-1574-8.

*Corresponding author: Liliya V. Poskotinova, PhD, ScD. Department of Biorhythmology of $N$. Laverov Federal Center for Integrated Arctic Research FCIARctic of the RAS, Arkhangelsk, Russia.E-mail: liliya200572@mail.ru 
13. Svendsen IS, Hem E, Gleeson M. Effect of acute exercise and hypoxia on markers of systemic and mucosal immunity. Eur J Appl Physiol. 2016;116(6):1219-29. doi: 10.1007/ s00421-016-3380-4.

14. Malik M, Bigger J, Camm A, Kleiger R, Malliani A, Moss AJ, Schwartz PJ. Task Force of the European Society of Cardiology and the North American Society of Pacing and Electrophysiology: Heart rate variability. Standards of measurement, physiological interpretation, and clinical use. Eur Heart J. 1996;17(3):354-381. doi: 10.1093/oxfordjournals.eurheartj.a014868.

15. Shaffer F, Ginsberg JP. An Overview of Heart Rate Variability Metrics and Norms. Front Public Health. 2017;5:258. doi: 10.3389/fpubh.2017.00258.

16. Millis RM, Austin RE, Hatcher MD, Bond V, Goring KL. Metabolic energy correlates of heart rate variability spectral power associated with a 900-calorie challenge. J Nutr Metab. 2011;2011:715361. doi: 10.1155/2011/715361.

17. Kazimierska A, Placek MM, Uryga A, Wachel P,
Burzyrnska M, Kasprowicz M. Assessment of Baroreflex Sensitivity Using Time-Frequency Analysis during Postural Change and Hypercapnia. Comput Math Methods Med. 2019:4875231 doi.org/10.1155/2019/4875231.

18. Hodges GJ, Ferguson SAH, Cheung SS. Cardiac autonomic function during hypothermia and its measurement repeatability. Appl Physiol Nutr Metab. 2019;44(1):31-36. doi: 10.1139/apnm-2018-0248

19. Wang JJ, Chen CC. Study of the effect of short-time cold stress on heart rate variability. In: Lim CT, Goh JC (eds) 13th International Conference on Biomedical Engineering. IFMBE Proceedings. 2009: 23: 490-492. doi.org/10.1007/978-3-54092841-6_120.

20. Shinjo T, Sakuraba K, Nakaniida A, Ishibashi T, Kobayashi M, Aono Y, Suzuki Y. Oral lactoferrin influences psychological stress in humans: A single-dose administration crossover study. Biomed Rep. 2018;8(5):426-432. doi: 10.3892/br.2018.1076. 